\title{
A Corpus-Based Study on Editorials
}

\author{
Maria Elena Chavez Villa \\ Asst. Professor, College of Arts and Sciences \\ Iloilo Science and Technology University, La Paz, Iloilo City \\ \{1'maelgacha@yahoo.com.\}
}

\begin{abstract}
The corpus of the study are English editorials with the theme Extra Judicial Killing. They were examined of their macrostructures or moves with reference to Hoey's four moves Problem-Solution model or McCarthy's three moves Claim-Counterclaim Model; and of their microstructures, the downtoner and subcategory according to Biber's. Intuitive and semantic analyses were done including the functions of the downtoner either intersententially or intrasententially. Results revealed there are editorials which moves are consistent to either Hoey's or McCarthy's, or both. Also, there are editorials which neither belong to either model, labeled as 'other.' Caesura(s) seemed inevitable making the writer not to hedge or downtone. This researcher proposes a label for caesurae, the relevant or ' $R$ ' move. An Intuitive Model is also proposed for the entire text. As to the downtoners, careful analysis is needed to unmask downtoner adverb occurring as adverb per se but functions either a conjunction or an adjective.
\end{abstract}

Keywords: Corpus; Corpus-based Study; Downtoner

\section{INTRODUCTION}

From the genre of English editorials of the local and of the national daily newspapers were the corpora of this study taken. These editorials convey a theme on "Extra Judicial Killing" and investigated of their macrostructures or moves and of their microstructures, the downtoners. The moves were identified and investigated. The microstructure units, the downtoners, were also identified according to Biber's categorization and determined of their functions either intersententially or intrasententially. Specifically, the study attempts to answer the following questions: 1. What organizational structure or pattern do newspaper editorials have? 2. What kind of downtoners are the most prevalently used in the newspaper editorials? 3. How do downtoners function intersententially and/or intrasententially? 4. What model of analysis can be proposed resulting from the study?

This study is anchored on the theory of Metadiscourse 'a discourse about a discourse' [1] which refers to the devices used intentionally by the writers to organize their texts, engage the readers and signal their attitude both to the text and their audience. This includes devices which help readers understand or guide them through a text and those which express a perspective towards either a proposition or readers. Another theory is Genre Analysis[2] which identifies the organizational structure through move analysis, the key linguistic feature of the text; and on the Corpus-based Approach to Discourse Analysis[3] resulting to generalized descriptions of discourse structure. 


\section{METHODOLOGY}

This covers the research design, the corpus, the unit of analysis, coding and framework for analysis, and the procedures in conducting the study.

This study uses descriptive design because of the investigation done on newspaper editorias both for its macro and micro structures addressing the 'what' questions that may arise as examination is done to the corpus and gives the implications of the findings [4]. Moreover, this study also employs the quantitative method in counting the frequencies needed. Data derived became the basis of the qualitative description of the present study.

For comparative study, the corpus of this study are ten English editorials taken from the nationally circulated newspaper, the Philippine Star, and ten from the regionally/locally circulated newspaper, the Panay News that convey one common theme, "the Extra Judicial Killing" (EJK). They were collected from the latest issue going backward until the number of issues needed were completely gathered.

The unit of analysis for the macrostructures are the sentence(s) or paragraphs investigated of their moves to determine the model. For the microstructure, the unit of analysis are the downtoners. These downtoners were classified/subcategorized based on Biber's categorization and examined of their function intersententially or intrasententially.

The organizational structure of the newspaper editorials was chunked using information reduction method to determine the macromoves. Two models were used: the Problem-Solution Model of Hoey[5] coded as ABCD and the Claim-Counterclaim Model of McCarthy[6] coded as EMA. Any pattern that deviated from these two macrostructure models was also coded and labeled "Other". For the microstructures, downtoners were classified and determined of their function intersententially or intrasententially. This classification showed the original syntactic status that determined the locus of the downtoner either as premodifier or subjunct adverbial upon which function first develops. Occurrences of these downtoners were also counted.

The procedure followed two levels of analysis. The first level is the macro-analysis consisted of coding the chunked parts in terms of their macro structures[7] using either the Problem-Solution Model or the Claim-Counterclaim Model. Through information reduction method,the editorial was chunked by into four organizational moves following the ProblemSolution Model and coded them ABCD. The first move, description of the situation (A) is the segment that talks about a current or recent issue. The second move, identifying the problem (B) is the section that discusses a concern or problem arising from the situation presented in the previous part of the text. The use of adversative marker but at the beginning of the paragraph must be noted. This and other markers (e.g. however) signal the second move in a Problem-Solution structure. To code the third move, describing the present solution (C), is to enumerate and to explain measures or steps to address the problem. This is usually signaled by markers such as modal auxiliaries (e.g. should, need to, will/shall have to). And the last move, evaluation of the solution (D), the segment of an editorials that assesses the viability or effectiveness of the proposed solution. The other model is Claim-Counterclaim Model of McCarthy[8] coded as EMA. The editorial was chunked by into three organizational moves the model. The moves are; (i) establishing a common ground (E) where the segment provides the reader with a background information that often comes from news stories; (ii) making a claim (M) where the segment conveys the editorial's stand on a current issue; and (iii) asserting a counterclaim (A) where the use of discourse marker however marks the counterargument.

The second level is the micro-analysis. The focus of micro-analysis in the present study is on syntactic structures of downtoners as used in the sentence. These downtoners were 
categorized based on Biber's classification and investigated of their function either intersententially or intrasententially. The downtoners were also searched electronically using the Navigation engine application of Microsoft Office 10 to be sure that all downtoners used in the text were appreciated. The semantic interpretation rules compute on the basis of these word meanings and the semantic structures whether the meaning of the whole sentence is 'well-formed' or the sentence is meaningful. [9]

\section{FINDINGS AND DISCUSSION}

Following the methodology and in particular to find solutions to the specific objective of the study, following are the findings:

Specific objective \#1: What organizational structure or pattern do newspaper editorials have? The Organizational structure or pattern of editorials on study are shown in the following table:

Table 1: Organizational Structure of the Newspaper Editorials from the Philippine Star and the Panay News

\begin{tabular}{|l|c|c|c|}
\hline Model/Code & Philippine Star & Panay News & Total \\
\hline Hoey's ABCD & 4 & 3 & 7 \\
\hline McCarthy's EMA & 5 & & 5 \\
\hline Others: & 1 & & \\
\hline ABCD/EMA & & 1 & 2 \\
\hline A A/B BCD/EMA & & 1 & 1 \\
\hline ABC/EM & & 1 & 1 \\
\hline ABXCXCDXD/EXMAX & & 1 & 1 \\
\hline EMXA & & 1 & 1 \\
\hline EMAXAX & 10 & 1 & 1 \\
\hline A/B B/CBCB & & 10 & 20 \\
\hline Total & & & \\
\hline
\end{tabular}

Table 1 shows that of the ten English editorials taken from the Philippine Star studied and examined, only four (4) editorials were consistent to the Problem-Solution Model of Hoey coded as ABCD; five (5) were consistent to the Claim-Counterclaim Model of McCarthy coded as EMA; and one has the moves of either Hoey's or McCarthy's thus coded as $\mathrm{ABCD} / \mathrm{EMA}$.

As to the editorials from the Panay News, Table 1 shows that three editorials were consistent to the four moves Problem-Solution model of Hoey coded as ABCD; one editorial has the macrostructures of both models coded as $\mathrm{ABCD} / \mathrm{EMA}$; one has the macrostructures following both models but lacks the last move of Hoey's model however compliant to McCarthy's model coded as AA/BCD/EMA, this editorial follows the two macrostructure models as shown by the locus of the moves and the semantics of the writer. Another editorial has the macrostructures of both models however lacks the last move of the models coded as $\mathrm{ABC} / \mathrm{EM}$, in here the writer did not convey his opinion over the issue on extending legal assistance to victims of EJK. It appears that this is a news editorial which is probably the reason why the organization is not consistent to the macrostructures according to either Hoey or McCarthy. Clearly, the writer just simply presented the information, or may be the facts, without taking a stand on the issue. Another editorial has the macrostructures of either ProblemSolution Model or Claim-Counterclaim Model but interrupted by unknown moves coded as ABXCXCDXD/EXMAX. This editorial was found having two different macrostructures. Indepth analysis of this editorial also revealed that there are moves which neither belong to any of the two models. This researcher labelled them ' $X$ ' to stand for the unknown. Semantic analysis 
shows that these X's convey either the direct or the indirect utterances of the writer's sources of information. Further analysis on the second part of this editorial shows that though coded as EMA, the structure of this editorial had been interrupted by unidentified move also coded as " $\mathrm{X}$ " to stand for unknown. A reader or an observer can deduce that this editorial does not follow the convention of editorial writing. Apparently, the structure exhibits the writer's stream of consciousness in writing as evidenced by quoting direct or indirect utterances of the sources of the information, thus, getting out of coherence on the matter. Another editorial followed McCarthy's Model but interrupted also by unknown move coded as EMXA, in here the locus of the moves were interrupted by $\mathrm{X}$ moves affecting the coherence of the text. It could be possible that the occurrence of X or X's may convey a new model for a structure of an editorial. In particular to the editorial, the writer used the transition "meanwhile" which, according to Merriam-Webster, means "at or during the same time; in the meantime." It tells us that the writer included another issue which may or may not have great and immediate or direct bearing to the main issue though happened at the same time. On the other hand, this researcher tried culling out from the said editorial all those paragraphs or moves marked $\mathrm{X}$ and the results showed that the revised version is a better presentation and comprehensible, coherence well defined and compliant to Claim-Counterclaim Model having the three moves. 1Another editorial following McCarthy's Model but extended and interrupted also by X unknown move coded as EMAXAX. The $\mathrm{X}$ moves show how the writer editor followed his stream of consciousness making the editorial appears to be a news article. These X moves don't have direct syntactical/functional relation to the development of the editorial. Even without them, the editorial could stand on its own having the complete parts or moves of McCarthy's model. It could be possible that the occurrence of X or X's may convey a new model for a structure of an editorial. Lastly, one editorial has an unusual move coded as A/BB/CBCB.

This study also finds that the Claim-Counterclaim Model of McCarthy consisting of three macrostructures can also be used in lieu of Hoey's Problem-Solution Model having four macrostructures. This is where the first move, establishing a common ground, according to McCarthy and the first move, description of the situation, according to Hoey, share the same locus in the editorials on study. The same findings apply to the last move of both models, e.g., asserting a counterclaim of McCarthy's and evaluation of the solution of Hoey's. As to the second move, making a claim of McCarthy's, its locus is shared by both the second and the third moves of Hoey's macrostructures such as identification of the problem and description of the present solution. Lastly, out of the ten editorials from the Panay News on study, none of which was compliant to the three-move macrostructure Claim-Counterclaim Model of McCarthy as shown with the interruptions of unidentified move.

Results of the analyses of the present study reveal that clarity and coherence of the moves and identification of the moves are well-defined in the Philippine Star than those of the Panay News. Apparently, the editorials of the Philippine Star reveal a collective opinion or point of view of the Editorial Staff of the newspaper company. For the Panay News, the macrostructures may have been intuitionally followed by the writer and possibly, since editorial carries the identity of the writer, expressing a fair view or nothing at all on the issue, is a better position knowing fully well the responsibility attached to being a commentary or being an editorial writer.

Specific objective \#2. What kind of downtoners are the most prevalently used in the newspaper editorials?

The following table shows the occurrences of downtoners in the English editorial of the Philippine Star and of the Panay Newspapers, so speaks of the prevalency of downtoners 
used in the editorials on study.

Table 2: Downtoners, per subcategory, as they appeared in the editorial of the PS and PN

\begin{tabular}{|c|l|l|c|}
\hline Downtoners & Philippine Star (PS) & Panay News (PN) & Total \\
\hline Approximator & almost (2) & 0 & 2 \\
\hline Compromiser & $\begin{array}{l}\text { enough (2) } \\
\text { rather (1) }\end{array}$ & $\begin{array}{l}\text { enough (2) } \\
\text { rather (1) } \\
\text { fairly (1) }\end{array}$ & 7 \\
\hline Diminisher & $\begin{array}{l}\text { but (10) (11) } \\
\text { only (5) }\end{array}$ & $\begin{array}{l}\text { only }(3) \\
\text { least (2) }\end{array}$ & 51 \\
& $\begin{array}{l}\text { just (2) } \\
\text { merely (1) } \\
\text { just (6) } \\
\text { justy (1) } \\
\text { to some extent (1) }\end{array}$ & \multicolumn{1}{|c|}{0} \\
\hline simply (1) \\
a little (1)
\end{tabular}

Table 2 shows that among the subcategories of downtoners, the diminisher is the most prevalently used, the compromiser with lesser frequency and least for approximator. The minimizer had never been used.

Among the diminishers, but is the most used in the editorials of Philippine Star and Panay News. The occurrences of but, which appear to be overused, support the statement that as an initial-sentence marker it expresses "semantic opposition" and "denial expectation" [10]; that but is an adversative marker [11] expressing a meaning that consists in more than marking a contrast between two conjuncts. "Semantic opposition" refers to formal contrast wherein something in the second conjunct semantically contrasts with something in the first conjunct. "Denial expectation" arises when the second conjunct is at odds with an expectation implied by the first clause; and that the corrective but is used to preface a correction to the previously and explicitly negated phrase [12]. Semantically, but does not allow minor reordering of clauses. The adverbial but does not link subordinate clauses because of its use in sentenceinitial position, and, unlike true coordinators, is not restricted to linking constituents of equal rank where it demonstrates a link between its clause and the whole of the preceding paragraph. Likewise, the coordinator but strongly implies contrast or negation, while the hallmark of the adverbial but is its implied concession considering its use as a sentence-initial adverbial that conveys a sense of concession[13]. Further investigation on the use of but as downtoner shows that it can be used intrasententially where the clauses connote in contrary to each other. In this study, but can be a conjunction, a preposition, etc. in addition to being an adverb, however but that occurred in this study but functions other than an adverb were not included in the results as shown in Table 2 .

Summarily speaking, comparing the use of downtoners between the editorials of the Philippine Star and the Panay News, editorial writers of the Philippine Star hedged more than those of the editorial writers of the Panay News. Clearly, it can be seen in the styles of the writers that those of the Philippine Star offered their opinion on the issue by downtoning while those of the Panay News hedged less because opinion is not offered rather facts are stated and utterances, either direct or indirect, of persons who are the source(s) of the statements were included. The inclusion of utterances affects the structure of the editorial and thus results to the editorial's inconsistency to the rule of coherence in the development of the text. This style actually runs counter to the idea that macrostructure or global structure of a discourse is as important as coherence in the same way as coherence is as important as the macrostructures of 
a discourse giving emphasis that "at the semantic level, the coherence of a discourse is determined also by macrostructures."'[14]

Further, the style of Panay News writers of hedging or downtoning less exhibits writer's potential as literary writer because of their style to follow their stream of consciousness and the style of using caesurae in the composition of the text manifesting their confidence in writing journalistically quoting statements, e.g., direct and indirect utterances, of sources. Moreover, this style also led the writer to develop the full text of the editorial without hedging or downtoning.

Specific objective \#3. How do downtoners function intersententially and/or intrasententially?

In this study, the locus of the downtoners shows their function as to either premodifier or subjunct adverbial. It enabled this researcher to immediately identify its function, however, caution was carefully observed as the downtoner may belong to an adverb but actually does not function as such, rather, functions as an adjective, a conjunction, etc. Thus, aside from spot identifying the function of the downtoner as to its locus, this researcher finds that the marker or the downtoner must be subjected to semantic investigation with careful attention to correctly appreciate its function.

Specific objective \#4. What model of analysis can be proposed resulting from the study?

In view of the foregoing findings, this researcher proposes a label to the unidentified move (X) as Relevant or "R". The Relevant (R) refers to the appropriateness or propriety of an element or section, or moves (for editorials) to be included to the development of the entire text. These X moves are either the direct or indirect utterances of the writer's sources or caesura employed by the writer as he develops the text Since these $\mathrm{X}$ moves are considered indispensable and to give justice to the skill of the writer in following his stream of consciousness having a caesura in the development of the text he is writing, the label ' $R$ ' for Relevant is proposed to name the $\mathrm{X}$ moves.

For macrostructure or global structure identification, this researcher is also proposing for a new model to be called an 'Intuitive Model' with a structure having three (3) components such as; Move 1, the Core $(\mathrm{C})$, this refers to the main, the primary, and the extremely important element(s) of the discourse; Move 2, the Important (I), includes element(s) of the discourse having serious meaning or worth that requires a special attention that could not just simply be ignored; and Move 3, the Relevant (R), that refers to the appropriateness or propriety for inclusion to the development of the entire text. The label of each move uses a simple and universal language that makes it comprehensible. This proponent names the model as 'Intuitive' because, basically, we use the intuition as basis for cognitive approach to study and to understand the global structures of the corpus or the text through the use of language and its eventual fruition for social interaction. This model shall serve as a compromise model that combines the structures of two models at the same time labels the unidentified inclusions to the structure of the text. This proponent also believes that 'Intuitive Model' may also apply to other genres of any opinionated text that may be subjected to discourse analysis like the argumentative essay. An editorial, on study, was analyzed using the proposed 'Intuitive Model' having three moves; the core (C); the important elements (I); and the relevant ideas (R), was found to be very applicable. 


\section{CONCLUSIONS}

As to the macrostructures of the editorials of the present study, this researcher found out that clarity and coherence of the moves are well-defined in the Philippine Star than those of the Panay News. Apparently, the editorials of the Philippine Star reveal the collective opinion or point of view of the Editorial Staff of the newspaper company. For the Panay News, the macrostructures are also observed however results of this study reveal that the macrostructures of an editorial may go less or beyond the moves of either Hoey's or McCarthy's. Unique to the editorials of the Panay News, there are editorials which go less or beyond the moves of either models however interrupted by unknown move(s), thus, coherence is affected. Others extended the macro structures with unknown moves. These editorials were labeled 'other' These findings support the statement that language use and behavior may be accounted for in independent theories, but these theories will ultimately be based on a theory of how language users and social participants perceive, interpret, know, memorize, evaluate, plan, produce, etc., their discourses and interaction. In other words, our social behavior including our communicative verbal interaction is determined by our interpretations and representations of social "reality." [15]

On the other hand, in-depth investigation of the editorials specifically on the semantics of downtoner led this researcher to conclude that the nature and function of the downtoners is a kind of hedging used by the writer or speaker when he or she wants to hint that what follows is different from what might have been supposed. However, this researcher has still seen some grey areas on the matter because just for the adversative marker but which in English is used for corrective function with two types of adversativity; restrictive and exclusive, has yet wide areas to be studied. Coordinators, subordinators and adverbs need special attention in the analysis as they can be confusing if not carefully and properly given attention especially in sentence-initial position. Doing so may pave to the development of new hypothesis that would be relevant and helpful in the future studies of a language or discourse analysis. In addition, semantic analysis enabled this researcher to recognize the multiplicity of functions of certain texts such as in the case of adverbs. Adverbs they may be per se, however, in-depth investigation reveals that they can function differently. With this condition, in-depth and semantic analysis needs careful attention so as to unmask downtoner adverb occurring as adverb per se but functions either as a conjunction or as an adjective. Since adverb is a function word modifying a verb, an adjective and another adverb, the same attention also may be given to adjective, also a function word modifying or describing a noun or a pronoun.

With these, there is still a wide room for more studies to be conducted to offer a clearer view of the subject matter or simply put, this study can still be replicated and the use of the proposed model is also recommended to prove its workability and effectiveness.

\section{Pedagogical Implications}

Using editorials for academic activities aids the teacher to engage his/her students into critical thinking and may, as well, lead them into reflective writing. It enables the students to have a perspective on issues that 'plagued' of 'disturbed' the placid condition of the country that would probably lead them to realize on something that may directly or indirectly affect their way of life. In addition, contemporary journalism could be of big help in the teachinglearning situation for reason of its authenticity and reliability. 


\section{References}

[1] Hyland, K. (2002). Teaching and Researching Writing. Great Britain: Pearson Education.

[2] Swales, J. (1990). Genre Analysis, English in academic and research settings. USA: Cambridge University Press, New York.

[3] Biber, d., U. Connor \& T. Upton (2007). Discourse on the Move: Using Corpus Analysis to Describe Discourse Structure. Amsterdam: John Benjamins.

[4] Shields and Rangarayan (2013). A Playbook for Research Methods: Integrating Conceptual Framework and Project Management. Stillwaters, OK: New Forums Press.

[5] Hoey's macrostructure Problem-Solution Model in Discourse Analysis

[6] McCarthy's macrostructure three moves Claim-Counterclaim Model in Discourse Analysis

[7] van Dijk, T. (1980). Macrostructure, An Interdisciplinary Study of Global Structures in Discourse, Interaction, and Cognition. New Jersey: Lawrence Erlbaum Asso., publishers.

[8] McCarthy's macrostructure three moves Claim-Counterclaim Model in Discourse Analysis

[9] van Dijk, T., ed. (1988). Discourse Studies: A Multidisciplinary Introduction. London: SAGE Publications Ltd.

[10] Lakoff, R. (1972). Language in Context Author(s): Language, Vol. 48, No. 4, pp. 907, Linguistic Society of America

[11] van Dijk, T., ed. (1988). Discourse Studies: A Multidisciplinary Introduction. London: SAGE Publications Ltd.

[12] Seah, SKB. (2014). Marker: as a multi-level objection marker: addressing issues raised by but - questions. Yale University.

[13] Kies, D. (1994). Adverbial but. Lake Bluff, II: Jupiter Press, pp. 315-332.

[14] van Dijk, T. (1980). Macrostructure, An Interdisciplinary Study of Global Structures in Discourse, Interaction, and Cognition. New Jersey: Lawrence Erlbaum Asso., Publishers.

[15] van Dijk, T., ed. (1980). Macrostructure, An Interdisciplinary Study of Global Structures in Discourse, Interaction, and Cognition. New Jersey: Lawrence Erlbaum Asso., Publishers.

\section{Biography}

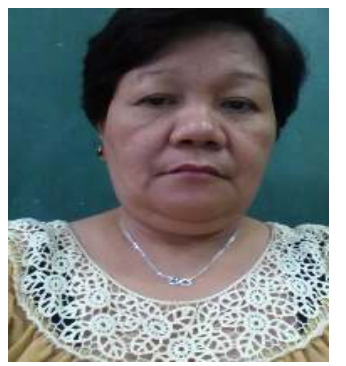

Maria Elena Chavez Villa is permanently residing in Iloilo City but a native of Sipalay City, Negros Occidental. She is on her post graduate studies taking Doctor of Philosophy in Applied Linguistics at the University of St. La Salle-Bacolod City, Negros Occidental. She completed her Master of Arts in Teaching Reading, Language and Literature also in the same university. Currently she is an Asst. Professor at Iloilo Science and Technology University (ISAT U), Iloilo City where she had been in service for almost 20 years teaching English and Literature courses. Prior to her tenure in this SUC, she was a College Instructor at the Western Institute of Technology, Iloilo City and at the Cabarrus Catholic College, Sipalay City also teaching English, Literature, and major courses in the English major program. Before her teaching career, she had worked as a 
Secretary to the Human Resource Department of a mining company in San Jose, Sipalay City, Negros Occidental for more or less 14 years. Mrs. Villa had been a member of the Board of Regents of ISAT U, had been the President of the Faculty and Employees Association of the same university, and is a member of the Confederation of Faculty Association of State Colleges and Universities of the Philippine. 